\title{
A primeira viagem científica brasileira: a Comissão Científica do Império
}

\author{
The first Brazilian scientific voyage: the \\ Imperial Scientific Commission
}

\author{
Maria Regina Cotrim Guimarães \\ Médica/Instituto de Pesquisa Clínica Evandro Chagas. \\ maria.regina@ipec.fiocruz.br
}

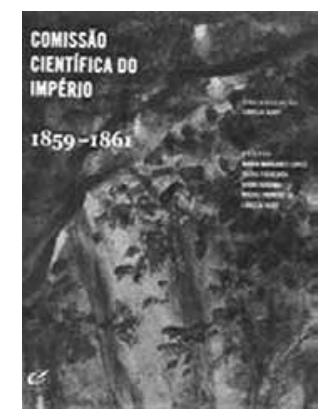

KURY, Lorelai (Org.). Comissão Científica do Império, 1859-1861. Rio de Janeiro: Andrea Jakobsson, 2009. 272p., 300 imagens. $\int \mathrm{s}$ desenhos e as aquarelas do livro Comissão Científica do Império, 1859-1861, organizado pela historiadora Lorelai Kury 150 anos após a primeira expedição científica nacional em direção aos sertões do Brasil, são um grande atrativo para o leitor. Presenteiam-no com os coloridos de paisagens, animais, plantas, igrejas, casas, tipos humanos, vestimentas e diversos objetos observados no Ceará e reproduzidos por cientistas e pintores participantes e organizadores da comissão.

Apesar de Portugal ter tentado esconder sua rica colônia americana das demais potências europeias, alguns relatos de viagens ao Brasil nos períodos de domínio holandês e francês geraram obras científicas. A partir do século XVIII, sob influência iluminista, Portugal mudou sua política em relação ao Brasil; promoveu pesquisas botânicas, estabeleceu algumas sociedades científicas e organizou expedições das quais participaram indivíduos da metrópole e da colônia. Entretanto, os viajantes oitocentistas mais conhecidos foram estrangeiros, como os alemães Spix e Martius, o francês Saint-Hilaire, o dinamarquês Lund e o suíço Agassiz. Suas observações tratavam da natureza e dos habitantes dos remotos interiores. Crenças, hábitos, práticas de cura, plantas e animais catalogados pelos viajantes renderam ao mundo alguns volumes de botânica e de zoologia que também refletiram o pensamento europeu sobre a condição de degeneração evolutiva dos indígenas do país.

Esse tipo de impressões dos viajantes naturalistas estrangeiros sobre o Brasil, entretanto, não serviria mais aos homens doutos do Império. Os letrados nacionais se viam na contingência de conhecer e entender o que acreditavam ser o verdadeiro Brasil, o verdadeiro homem brasileiro, o verdadeiro ambiente brasileiro e a verdadeira cultura brasileira.

As instituições imperiais do Brasil consolidaram-se nos meados dos Oitocentos, com a produção de um conhecimento científico ao mesmo tempo local e legitimado por pressupostos europeus. O Imperial Observatório do Rio de Janeiro, o Instituto Histórico e Geográfico Brasileiro (IHGB), a Academia Imperial de Medicina, as faculdades de Medicina do Rio de Janeiro e da Bahia e o Museu Histórico Nacional, exemplos de espaços de apoio e de concretização de inúmeras pesquisas, davam o caráter civilizador às ciências e aos cientistas do Brasil. 
O Império, influenciado tanto pelo iluminismo racionalista como pelo romantismo nacionalista, importou-se em conhecer, sob o prisma institucional, o Brasil que então (se) construía. O espírito romântico estimulava o encontro das raízes brasileiras no 'bom selvagem' local, o índio - até então associado ao atraso e à incivilidade. Assim, com a perspectiva de corrigir as impressões dos naturalistas estrangeiros e de buscar uma identidade nacional, o IHGB se encarregou de formar a primeira comissão nacional de cientistas brasileiros a fim de explorar as regiões pouco conhecidas do Brasil e obter um retrato da verdadeira condição dos indígenas à época.

As viagens científicas são, há algumas décadas, uma área de especial interesse para a história das ciências; a obra Comissão Científica do Império, 1859-1861 analisa as circunstâncias, as motivações, os resultados, os descaminhos e os desdobramentos dessa expedição constituída por cinco seções de grande interesse para o governo imperial: botânica; geologia e mineralogia; zoologia; astronomia e geografia; e etnografia. Apesar de representantes de circunspectas instituições do Império, alguns dos cientistas da comissão, fundamentais na empreitada, e cada qual ao seu modo, são apresentados por cinco historiadoras como personagens bem vivos, em suas aventuras e desventuras.

A introdução do livro, escrita por Lorelai Kury, tem o título "Explorar o Brasil: o Império, as ciências e a nação" e apresenta os demais capítulos do livro como uma reflexão sobre o passado e o presente dos cientistas brasileiros. Situa os relatórios dos viajantes da comissão no ideal civilizatório do Império do Brasil e no de invenção da identidade nacional.

Como os cientistas da comissão acreditavam em um Brasil maravilhoso, acharam por bem fazer oposição às falsas impressões divulgadas pelos naturalistas estrangeiros. Munidos de conhecimento científico e da fé na existência de riquezas minerais, dirigiram-se à então província do Ceará. O Ceará sintetizava a ideia de norte e de interior, características que o IHGB concebia como o pressuposto dessa viagem.

O capítulo “A Comissão Científica de Exploração: uma 'expansão para dentro'”, de Maria Margaret Lopes, analisa a viagem como parte de um empreendimento amplo do Império, com continuidade, permanência e desdobramentos, de que tinham consciência os cientistas aí envolvidos. As viagens, desde o final do século XVIII, se integraram no processo de profissionalização de cientistas e de constituição de disciplinas que até então foram acessórias na formação de engenheiros e médicos, como botânica, zoologia, geologia e etnografia.

A comissão foi precedida de intensos preparativos que refletiram a seriedade da empreitada, como a compra de importante bibliografia, de material para a ilustração, de aparelhagem - como telescópio, planímetro, microscópio, barômetros, termômetros e vidraria - e da criação das ambiciosas "Instruções para a viagem". As instruções foram feitas com base nos programas disciplinares da época adaptados ao que os cientistas viajantes consideravam urgências do país. Essas seriam o incremento da agricultura, a atenção para o aproveitamento de qualquer recurso para a indústria emergente (rendas e couros, indústria indígena, mel de abelhas, madeira), a abertura de vias de comunicação entre o interior e o litoral, o aproveitamento dos minerais, além das informações oriundas dos conhecimentos tradicionais e populares, como conversas com as populações locais sobre lendas de ouro encantado, antigas lagoas, línguas indígenas, e usos e costumes. 
Apesar de as instruções terem orientado a viagem de forma conjunta, a comissão se dividiu em três, para a sua permanência no Ceará. As seções Geológica e Etnográfica seguiram viagem juntas, assim como a Botânica e a Zoológica. A Seção Astronômica foi a que mais sofreu cortes de verbas, mas determinou posições de diversas vilas, reuniu dados para uma carta itinerária da província e registrou observações para o estudo do clima e resolução de problemas agrícolas. A comissão, com os relatórios gerados durante a viagem, ainda que muitos tenham sido perdidos, cumpriria o propósito do governo imperial de mapeamento do território e das populações locais, na perspectiva do que a autora chamou de "expansão para dentro".

O capítulo "Areias, ventos e secas: ainda assim um 'Eldorado' à brasileira", de Silvia Figueiroa, é uma análise de 32 artigos da coluna do Diário do Rio de Janeiro chamada de "Zig-zag da seção geológica da commissão scientifica do norte", e de apontamentos sobre a seca, escritos pelo chefe da Seção Geológica, o barão de Capanema. Esse engenheiro com grande conhecimento da história natural valorizou a observação dos fenômenos em relação à especulação teórica e criou explicações para o que encontrava de interessante pelo caminho, como a formação de cavernas a partir da erosão e soluções para os problemas oriundos do movimento das areias que desviavam cursos de água.

Bem na medida das preocupações da elite intelectual do Império, o barão de Capanema elevou o elemento local e nacional e sugeriu aproveitamento econômico para os objetos encontrados - como a possibilidade de se industrializar uma flor, a angélica, pelo seu cheiro agradável, em substituição aos perfumes europeus. A linguagem de seus escritos é simpática aos menos doutos, mesclando o conhecimento científico às suas observações diárias. O ideal de produzir uma ciência local e acessível aos leitores - que, ainda assim, eram uma pequena parcela da população - foi perseguido por Capanema.

Na perspectiva ao mesmo tempo nacionalista, civilizadora e eurocêntrica de seu tempo, Capanema reconheceu até mesmo na seca do Nordeste um problema comparável aos invernos europeus, nos quais a vida não seria menos desafiada. Aí, o ideal romântico nacionalista aflorava: passada a seca, a vegetação rapidamente surgia, a seu ver, de forma maravilhosa.

Quando foi convocado para conduzir a Seção Etnográfica e redigir a narrativa da comissão, o escritor Gonçalves Dias estava na Europa a serviço do governo brasileiro, estudando a instrução pública e documentos históricos sobre o Brasil. Seu trabalho e sua seção foram analisados por Kaori Kodama, no capítulo "Em busca da gênese do Brasil nas províncias do Norte: Gonçalves Dias e os trabalhos etnográficos da Comissão Científica de Exploração". As estreitas relações entre etnografia e história na produção de conhecimento, no período, são percebidas no trabalho de Gonçalves Dias, que possuía prática em lidar com arquivos e em registrar informações orais sobre acontecimentos importantes dos locais e sobre estatísticas populacionais, ao mesmo tempo em que se dedicou ao estudo das línguas indígenas. Fazia parte dos estudos etnográficos, à época, um mapeamento do que as ciências entendiam como raças humanas; no caso, tratava-se de conhecer a organização social e as línguas dos índios, de preservar objetos e culturas em vias de desaparecimento, e, de forma especial, vislumbrar formas de incorporar as populações locais à massa de trabalhadores. Respeitando os preceitos civilizadores do Império, os viajantes acreditavam que já estava extinto da região o elemento indígena 'puro' e entendiam a necessidade de se integrarem os agora mestiços no universo cristão do progresso nacional. 
A preocupação da comissão com o que havia de exótico nas populações locais dizia também respeito à questão da cultura popular. Costumes, festas, línguas, detalhes da cultura material, cada elemento estranho aos viajantes era digno de registro com vistas ao entendimento do local e do país, não só por Gonçalves Dias e pela Seção Etnográfica, como por grande parte dos viajantes da comissão.

A “Zoologia da Comissão Científica de Exploração" é capítulo de Magali Romero Sá, que analisa essa seção por meio do trabalho de Manuel Ferreira Lagos, bem relacionado nas instituições imperiais e autor das "Instruções relativas à zoologia". Lagos considerava que a tarefa de sua seção, além da coleta e classificação de animais, seria priorizar suas aplicações econômicas e farmacêuticas, o que era coerente com as instruções. A preocupação de Lagos com a utilidade econômica da fauna em detrimento dos estudos zoológicos propriamente ditos rendeu-lhe algumas críticas. Lagos pensou mais na pesca do que nos peixes, observou a atividade pecuária, pesquisou as sanguessugas terapêuticas, entendeu a entomologia pelo viés de insetos úteis na fabricação de corantes, seda, mel e cera. Para ele, a natureza teria que ser domada e servil, portanto, de utilidade social e econômica. O inventário zoológico local era função dos coletores e preparadores da seção.

Apesar do seu forte viés etnográfico, Lagos se interessou pelas coleções científicas, pelo acondicionamento e preparação dos espécimes e pelos detalhes nos desenhos de história natural. Uma parte importante da coleção foi perdida, mas Lagos registrou em seu relatório a perfeição da montagem pelos irmãos Villa Real das aves que depois seriam expostas no Museu Nacional. Ainda que Lagos não tenha produzido qualquer estudo sobre a fauna coletada, sua visão pragmática e antropocêntrica da ciência refletia a preocupação das instituições imperiais com a associação entre os ideais de nação e de progresso científico.

O capítulo "Francisco Freire Alemão, botânico e viajante", de Lorelay Kury, trata do trabalho daquele que foi conselheiro do Império, médico da família imperial e presidente da comissão e da Seção Botânica. Freire Alemão incorporou o seu papel de representante do governo imperial, pois era grato ao imperador pelos espaços sociais que alcançara. Influenciado por Saint-Hilaire e Martius, sua trajetória indica também um importante momento da construção das ciências do Brasil; tudo o que vivera ou registrara no Ceará integrava a mesma nação a que ele próprio pertencia.

A intenção de seu trabalho foi mapear o reino vegetal segundo a biogeografia; à medida que os viajantes caminhavam para o interior do Ceará e que a paisagem mudava, Freire Alemão percebia mudanças também na vegetação, o que relatava e registrava em desenhos. Da coleta, conservação e desenhos colaboraram seu sobrinho Manoel e o pintor José dos Reis Carvalho, mas o próprio Freire Alemão conhecia, além das técnicas botânicas, a da gravura, o que vinha a calhar, pois nem sempre poderia remunerar artistas para que fizessem os registros de suas observações.

A sensibilidade do conselheiro para as observações etnográficas chama a atenção em seus escritos. Tal como ocorreu com alguns colegas da expedição, seu objetivo ia além da coleta e conservação de espécimes botânicos, pois conversava com as populações locais sobre assuntos que considerava úteis para conhecê-las melhor, como seus costumes e o ambiente em que viviam. 
O conselheiro contribuiu também para que se entendessem as relações difíceis entre os participantes da comissão, o que pode ajudar a explicar a decisão de se construírem diferentes itinerários e se separarem as diversas seções, ainda no início da viagem.

O livro Comissão Científica do Império, 1859-1861 analisa o trabalho dos cientistas-viajantes sob uma perspectiva bem diferente daquela que chegou à opinião pública da época, e que tratou a comissão, ironicamente, por Comissão das Borboletas. A comissão gerou expectativas, particularmente relacionadas ao encontro de riquezas minerais, o que não se confirmou. Para muita gente que observou de longe, foi difícil aceitar que um gasto vultoso de dinheiro com atividades científicas resultasse 'apenas' em relatórios e algumas exposições.

Os resultados imediatos da comissão apareceram em notícias de jornais e em uma exposição realizada em 1861, no Museu Nacional, com produtos do Ceará que foram levados, no ano seguinte, para a Exposição Universal de Londres. A maior contribuição da comissão, entretanto, estaria relacionada às estratégias de construção de uma ciência nacional e de criação de identidades regionais na segunda metade do século XIX.

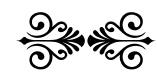

